\title{
3 Research Square \\ Eradication of Klebsiella Quasipneumoniae By Eudragit-Formulated Klebicin Kvaria In The Intestinal Tract of Mice
}

Indre Karaliute

Lithuanian University of Health Sciences

Rima Ramonaite

Lithuanian University of Health Sciences

Jurga Bernatoniene

Lithuanian University of Health Sciences

Vilma Petrikaite

Lithuanian University of Health Sciences

Audrius Misiunas

Nomads UAB

Erna Denkovskiene

Nomads UAB

Ausra Razanskiene

Nomads UAB

Yuri Gleba

Nomad Bioscience GmbH, Biozentrum Halle

Juozas Kupcinskas

Lithuanian University of Health Sciences

Jurgita Skieceviciene ( $\sim$ jurgita.skieceviciene@lsmuni.It)

Lithuanian University of Health Sciences

\section{Research Article}

Keywords: Klebsiella quasipneumoniae, klebicins, Kvarla, haemolysin gene, bacteriocins

Posted Date: December 22nd, 2021

DOI: https://doi.org/10.21203/rs.3.rs-1075190/v2

License: (c) (1) This work is licensed under a Creative Commons Attribution 4.0 International License.

Read Full License 


\section{Abstract}

Background: Klebsiella quasipneumoniae is an opportunistic pathogen causing antibiotic-resistant infections of the gastrointestinal tract in many clinical cases. Orally delivered bioactive Klebsiella-specific antimicrobial proteins, klebicins, could be a promising method to eradicate Klebsiella species infecting the gut.

Methods: Mouse infection model wasestablished based on infection of streptomycin treated BALB/C mice with K. quasipneumoniae strain DSM28212. Four study groups were used (3 animals/group) to test the antimicrobial efficacy of orally delivered klebicin Kvarla: vehicle-only group (control, phosphatebuffered saline), and other three groups with bacteria, antibiotic therapy and $100 \mu \mathrm{g}$ of uncoated Kvarla, $100 \mu \mathrm{g}$ coated Kvarla, $1000 \mu \mathrm{g}$ coated-Kvarla. Because of the general sensitivity of bacteriocins to gastroduodenal proteases, Kvarla doses were coated with Eudragit@, a GMP-certified formulation agent that releases the protein at certain $\mathrm{pH}$. The coating treatment was selected based on measurements of mouse $\mathrm{Gl}$ tract $\mathrm{pH}$. The quantity of Klebsiella haemolysin gene $(k h e)$ in faecal samples of the study animals was used to quantify the presence of Klebsiella.

Results: GI colonization of $K$. quasipneumoniae was achieved only in the antibiotic-treated mice groups. Significant changes in khe marker quantification were found after the use of Eudragit ${ }^{\circledR} \mathrm{S} 100$ formulated klebicin Kvarla, at both doses, with a significant reduction of $K$. quasipneumoniae colonization compared to the vehicle-only control group.

Conclusions: Mouse GI tract colonization with K. quasipneumoniae can be achieved if natural gut microbiota is suppressed by prior antibiotic treatment. The study demonstrates that GI infection caused by $K$. quasipneumoniae can be significantly reduced using Eudragit ${ }^{\circledR}$-protected klebicin Kvarla.

\section{Background}

Klebsiella is a gram-negative and anaerobic bacterium of the Enterobacteriaceae family that colonizes various environmental niches including normal flora of the human mouth or intestines $[1,2]$. Pathogenic Klebsiella species, such as $K$. pneumoniae and $K$. oxytoca, are the most prevalent infections acquired in hospital (HAl) [2,3]. Recent studies have identified $K$. quasipneumoniae as a new species distinguishable from $K$. pneumoniae. $K$. quasipneumoniae has been shown to act as an etiological agent in a number of clinical Klebsiella-related infection cases, but has often been misidentified as $K$. pneumoniae in HAI [4,5]. $K$. quasipneumoniae colonizes the intestinal tract, which can lead to virulent urinary tract and abdominal infections [3-6]. Furthermore, this type of bacteria shows high rates of resistance against antibiotics, and has been characterized as pan-drug resistant, making these infection extremely difficult to treat $[7,8]$. For this reason, the development of new antimicrobial agents is required to mitigate bacterial infections, typically acquired by patients while in-hospital.

Colicin-like bacteriocins, produced by gram-negative bacteria, may be a potential alternative to traditional antibiotics $[9,10]$. Colicin-like bacteriocins are a heterogeneous family of proteinaceous toxins, which are 
capable of killing closely related bacteria, those belonging to the same species or, sometimes, the same genus [11]. This property makes them attractive as therapeutics since they offer a more targeted approach than conventional antibiotics. Indeed, one of the major issues with conventional antibiotics is the dysbiosis induced by the broad-range killing of bacteria [12,13]. Most importantly, the mechanisms of bacterial killing by bacteriocins are fundamentally different from those by antibiotics. Consequently, they are active against multi-drug and pan-drug resistant pathogens.

The authors have previously identified and characterized several Klebsiella bacteriocins, which exhibit significant and broad activity against the pathogenic Klebsiella species [14]. Orally delivered klebicins have a potential as an excellent means to eradicate intestinal infections in hospitalized patients that are caused by the multidrug-resistant Klebsiella strains. However, the proteinaceous nature of bacteriocins makes them susceptible to quick inactivation by gastroduodenal enzymes. Therefore, for the oral administration of klebicins, they must be encapsulated or formulated for gastroduodenal protection, for the release in the small and large intestine.

In this study, we developed a mouse model of $K$. quasipneumoniae intestinal colonization, tested the $\mathrm{pH}$ condition of the mouse GI tract, and established a suitable coating for klebicin Kvarla. We also evaluated the antimicrobial activity of the orally delivered Eudragit S100-formulated klebicin in the mouse intestinal tract. We confirmed that, even without further bacteriocin engineering and improvement, bacteriocins could be employed as oral antimicrobials for efficient control of antibiotic-resistant Klebsiella.

\section{Methods}

Aim of this study: To investigate the antimicrobial effectiveness of the klebicin Kvarla in a mouse model of K. quasipneumoniae gastrointestinal (GI) colonization.

Mouse models: Two separate experimental settings of the murine models were used for $K$. quasipneumoniae colonization and Kvarla treatment. For both models, 8-10 weeks old, BALB/c strain, female $(n=8 ; 19-25 \mathrm{~g})$ and male $(n=16 ; 22-27 \mathrm{~g})$ mice were purchased from the Lithuanian University of Health Sciences vivarium of laboratory animals. All regulated procedures on living animals were approved by The Lithuanian Ethics Committee of Biomedical Research (Protocol no. G2-119).

\section{GI model of $K$. quasipneumoniae (DSM28212) colonization and Kvarla therapy: Klebsiella}

quasipneumoniae clinical isolate DSM28212 was used for GI tract colonization in four different study groups containing three mice per group $(m=2 ; f=1)$. Vehicle-only control group was monitored for any changes in the natural host-microbiota without any additional procedures during the period of the experiment. The ability of $K$. quasipneumoniae to colonize the $\mathrm{GI}$ tract without antibiotic pre-treatment to disrupt the host-microbiota was tested. In order to mimic hospital-acquired infections two groups were given different combinations of antibiotic treatment before infection (penicillin $(2000 \mathrm{U} / \mathrm{ml})+$ streptomycin $(2 \mathrm{mg} / \mathrm{ml})$, (pen_strep); penicillin $(2000 \mathrm{U} / \mathrm{ml})+$ streptomycin $(2 \mathrm{mg} / \mathrm{ml})+$ metronidazole $(1$ $\mathrm{g} / \mathrm{L})$ (pen_strep_met)) (study design in 1A fig.). For Kvarla therapy testing three groups $(\mathbf{A} ; \mathbf{B} ; \mathbf{C})$ received 
$10^{9} \mathrm{cfu}$ of $K$. quasipneumoniae orally by pipette feeding once per day. From day 18th group A was given $100 \mu \mathrm{g}$ of uncoated Kvarla, groups B and C were given $100 \mu \mathrm{g}$ and $1000 \mu \mathrm{g}$ of Eudragit S100-coated Kvarla respectively (detailed study design 2A fig.). For each mouse, faecal pellets were sampled.

Determination of $\mathrm{pH}$ of the gastrointestinal tract: As shown in figure $1 \mathrm{~A}$, the samples of rectum excreta were collected on six different days during the experiment. Acquired samples were homogenized with deionized water (1:10 ratio) and $\mathrm{pH}$ was determined using $\mathrm{pH}$ METER Mettler Toledo (Belgium) with the Inlab Ultra-Micro electrode. In addition, the $\mathrm{pH}$ was measured in the samples taken from the GI tract during the laparotomy dissection (the intestinal tract was divided into three sections: the stomach, the duodenum, and the rectum).

Klebicin production in plants and purification: Klebsiella bacteriocin Kvarla was expressed in Nicotiana benthamiana transient expression system and purified as previously described in Denkovskiene et al [14].

Coating of Kvarla: $5 \%$ Eudragit S100 solution was prepared by dissolving $0.5 \mathrm{~g}$ Eudragit S100 (Evonik Industries, Germany) in $10 \mathrm{ml}$ of miliQ $\mathrm{H}_{2} \mathrm{O}$ and by sonication in an ultrasonic bath for $30 \mathrm{~min}$ at $25^{\circ} \mathrm{C}$. $250 \mu \mathrm{g}$ of Kvarla was dissolved in $200 \mu \mathrm{g}$ of $5 \%$ Eudragit S100. The obtained solution was lyophilized at $-51^{\circ} \mathrm{C}$ for $24 \mathrm{~h}$.

\section{Simulated gastric digestion and residual Kvarla activity evaluation by soft agar radial diffusion}

assay: Protein samples (Kvarla and Eudragit S100-coated Kvarla) were dissolved in simulated gastric buffer $(0.15 \mathrm{M} \mathrm{NaCl}, \mathrm{pH} 2)$, at a concentration of $1 \mathrm{mg} / \mathrm{ml}$ and incubated at $37^{\circ} \mathrm{C}$ with rotation at $200 \mathrm{rpm}$ for $10 \mathrm{~min} .0 .025 \mathrm{mg}(80-113 \mathrm{U})$ of pepsin from porcine gastric mucosa was added to $1 \mathrm{mg}$ of protein (pepsin:protein ratio 1:40). Aliquots of reaction (50 $\mu$ ) were removed at different time points (0.5 min, 5 $\mathrm{min}, 10 \mathrm{~min}, 20 \mathrm{~min}, 30 \mathrm{~min}$, and $60 \mathrm{~min}$ after the addition of the pepsin). Digestions were stopped by raising the $\mathrm{pH}$ to 6.5 by the addition of $0.5 \mathrm{M}$ ammonium bicarbonate to inactivate pepsin. The $\mathrm{pH}$ of samples was adjusted to 8.0 to get Eudragit S100 coat dissolved. The dilutions of all samples by ratio $1: 2$ were made in distilled water and $5 \mu \mathrm{L}$ drops of diluted samples were applied on K.quasipneumoniae DSM28212 MHA plates for soft agar overlay assay.

Soft-agar overlay assays were performed as described by Denkovskiene et al [14], with some modifications. K. quasipneumoniae DSM28212 overnight culture was equalized to $\mathrm{OD}_{595}=1.0$ in MullerHinton medium and diluted 100 -fold in $0.8 \%(\mathrm{w} / \mathrm{v})$ top agar preheated in a $55^{\circ} \mathrm{C}$ water bath. Mixed overlay components were poured on plates containing solid medium (Muller-Hinton containing $1.5 \%$ $(\mathrm{w} / \mathrm{v})$ agar). Sterile Whatman paper discs (6 $\mathrm{mm}$ diameter) were placed on the surface of the soft-agar medium containing bacterial test strain and $5 \mu \mathrm{l}$ of protein dilutions were applied to the discs. The plates were incubated overnight at $37^{\circ} \mathrm{C}$ and the diameter of klebicin inhibition zones was measured.

Briefly, plant-produced Kvarla and Eudragit S100-coated Kvarla were mixed with SGF at the recommended concentration and incubated for up to $60 \mathrm{~min}$, sampling every few minutes and assessing the digestion of the protein into fragments by SDS-PAGE. Coomassie staining on gels was used to visualize protein 
decomposition and estimate the MW of peptide products. This method was only used for uncoated Kvarla, as Eudragit S100 distorted protein migration on the SDS-PAGE gel.

Nucleic acid extraction and synthesis of the CDNA: Bacterial DNA and RNA from rectum excrement samples were extracted using the AllPrep PowerFecal DNA/RNA Kit and AllPrep DNA/RNA Mini Kit (Qiagen, Germany). 100 mg of faeces sample were used for the extraction procedures. The quantity and quality of extracted nucleic acids were evaluated by NanoDrop 2000 (Nanodrop Technologies, Wilmington, DE, USA). Subsequently, cDNA was synthesized using a High-Capacity cDNA Reverse Transcription Kit (Thermo Fisher Scientific, Lithuania). $18 \mathrm{ng}$ of cDNA was added into the qualitative realtime PCR (qRT-PCR) reaction. All processes were completed upon the manufacturer's instructions.

Quantitative assessment of Klebsiella quasipneumoniae using Real-Time - PCR: The haemolysin gene (khe) was chosen as the qualitative marker for Klebsiella identification $[15,16]$. The standard curve was created based on DNA samples of K. quasipneumoniae (DSM28212) to test the generated primers' efficiency. DNA-based standard curve. $10^{3}, 10^{5}, 10^{6}, 10^{8}, 10^{9}$, and $10^{10} \mathrm{CFU}$ of $K$. quasipneumoniae in 200 $\mu$ were subjected to DNA extraction with QIAamp Fast DNA Stool Mini Kit (protocol for liquid sample).

During this step, the reaction for the qRT-PCR was performed using TaqMan Universal Master Mix II with UNG, TaqMan probe (5-6FAM-CGCGAACTGGAAGGGCCCG-TAMRA-3), and primers (Forward: 5 GATGAAACGACCTGA TTGCATTC-3, Reverse: 5 -CCGGGCTGTCGGGATAAG-3 (Applied Biosystems, JAV) following the manufacturer's recommendations. The amplification of the khe gene was determined by ABI Fast 7500 System (Life Technologies, Carlsbad, CA, USA) according to standard protocol. Positive controls for DNA and RNA were isolated from $K$. quasipneumoniae and negative - isolated from E. coli.

Statistical analysis: The data were analysed using nonparametric tests. The difference between the four protocols groups throughout the layout of the experiment were analysed using Student's independent $t$ test. Independent analyses were carried out using SPSS Version 19.0 and MiniTab 20.1.2 software packages. Results were considered statistically significant when $p<0.05$ with $\pm 95 \%$ confidence intervals.

\section{Results}

Selection of bacteriocin Kvarla coating by $\mathrm{pH}$ measurements along the GI tract: In order to determine the efficient coating and delivery of the klebicins in the $\mathrm{Gl}$ tract, firstly we performed the $\mathrm{pH}$ measurements in faeces and along the $\mathrm{Gl}$ tract. The $\mathrm{pH}$ of the faecal samples is shown in figure 1B. The lowest $\mathrm{pH}$ was seen after penicillin, streptomycin, and metronidazole treatment. Nonetheless, there was no observation of any statistically significant changes in $\mathrm{Gl}$ tract $\mathrm{pH}$ between groups (average mean $\pm \mathrm{SD}$ : vehicle-only control group 7.3 \pm 0.52 ; bacterial control group $7.5 \pm 0.74$; pen_strep group $7.7 \pm 0.29$; pen_strep_met group $7.4 \pm 0.62)$. The $\mathrm{pH}$ levels of the different $\mathrm{GI}$ tract sections was also measured after the mouse decapitation (the stomach $3.3 \pm 0.92$, small intestine $6.5 \pm 0.34$, the large intestine $7.4 \pm 0.42 ; 1 \mathrm{C}$ fig.) The significant differences in $\mathrm{pH}$ measures were found between the vehicle-only control group and pen_strep group $(p=0.004)$ in duodenum, vehicle-only control group and pen_strep_met group $(p=0.04)$ in rectum. 
Eudragit \$100-coated Kvarla is partially protected from digestion by simulated gastric fluid: To find out if Eudragit S100-coated Kvarla is resistant to pepsin digestion, a simulated gastric digestion experiment was performed. Exposures of the proteins to Simulated Gastric Fluid (SGF, commercial acidic pepsin extract) were done using low enzyme-to-substrate ratios in order to increase the stringency and relevance of the digestibility assays. Methods were derived from (Moreno 2005; Mandalari 2009; Eiwegger 2006).

It appears, that in conditions used (pepsin:protein ratio 1:40), protein coating with Eudragit $\mathrm{S} 100$ is able to provide temporal resistance to pepsin digestion. Coated Kvarla demonstrated still detectable activity in agar diffusion assay after 20 min of in vitro gastric digestion, while uncoated Kvarla was inactivated in simulated gastric juice very quickly, and completely lost its activity already after 0.5 min of digestion (3 fig.). From the SDS-PAGE profile of uncoated Kvarla digestion products, it is apparent that uncoated klebicin in digested by pepsin very rapidly.

\section{Colonization of mice gut by $K$. quasipneumoniae is achieved only after disruption of natural}

microflora: The GI tract infection/colonization model was established in mice using Klebsiella quasipneumoniae. It was designed to reflect bacterial colonization in the host after the disruption of natural microflora with antibiotics therapy. There was no colonization of $K$. quasipneumoniae observed in the vehicle-only control group. The use of antibiotic pre-treatment ((i) penicillin, streptomycin or (ii) penicillin, streptomycin, and metronidazole), in order to disrupt the host microbiota, resulted in introduction of $K$. quasipneumoniae $\left(4^{\text {th }}\right.$ day no bacterial counts were found $(0 \mathrm{CFU} / 70 \mathrm{mg})$; (i) $8^{\text {th }}$ day $5.25 \times 10^{8} \mathrm{CFU} / 70 \mathrm{mg}, 11^{\text {th }}$ day $-3.01 \times 10^{8} \mathrm{CFU} / 70 \mathrm{mg}$ and (ii) $8^{\text {th }}$ day $-5.13 \times 10^{8} \mathrm{CFU} / 70 \mathrm{mg}$ and $11^{\text {th }}$ day - $3.89 \times 10^{8} \mathrm{CFU} / 70 \mathrm{mg}$ ) (2 fig.). Our data showed that colonization of mice gut by $K$. quasipneumoniae can be established after eradication of natural gut microflora.

Eudragit S100-coated Kvarla efficiently reduces $K$. quasipneumoniae amount in colon: We evaluated the effectiveness of Eudragit S100-coated Kvarla $(100 \mu \mathrm{g} ; 1000 \mu \mathrm{g})$ in K. quasipneumoniae infection model. Three different combinations of recombinant klebicin were used: uncoated-Kvarla, Eudragit S100-coated Kvarla $100 \mu \mathrm{g}$, and Eudragit S100-coated Kvarla $1000 \mu \mathrm{g}$. The amplification of the khe marker gene was significantly higher in both Eudragit S100-coated Kvarla-treated mice groups than in the control (PBS) and uncoated-Kvarla-treated mice on the last day of the experiment $\left(22^{\text {nd }}\right.$ day). As shown in figure 4 the bacterial counts were significantly lower after the treatment with Eudragit S100-coated Kvarla $100 \mu \mathrm{g}$ and $1000 \mu \mathrm{g}$ in contrast with the samples taken on the first day of bacteriocin administration ( $18^{\text {th }}$ day). The amounts of $K$. quasipneumoniae changed from $6.3 \times 10^{7} \mathrm{CFU} / 50 \mathrm{mg}$ on the $18^{\text {th }}$ day to $3.9 \times 10^{5}$ CFU/50mg on the $22^{\text {nd }}$ day $(p=0.01)$ in the Eudragit S100-coated Kvarla $100 \mu \mathrm{g}$ group and from $4.0 \mathrm{x}$ $10^{7} \mathrm{CFU} / 50 \mathrm{mg}$ on the $18^{\text {th }}$ day to $1.6 \times 10^{5} \mathrm{CFU} / 50 \mathrm{mg}$ on $22^{\text {nd }}$ day $(\mathrm{p}=0.009)$ in the Eudragit S100coated Kvarla $1000 \mu \mathrm{g}$ group. No significant changes in bacterial counts were seen in the vehicle-only control group (PBS) and after the administration of uncoated-Kvarla.

\section{Discussion}


A rapidly increasing number of antibiotic-resistant and/or highly virulent bacterial strains is a serious challenge faced by today's healthcare system worldwide. Recent studies indicate that patients, with hospital-acquired multidrug-resistant $K$. pneumoniae infection, have a significantly higher risk of developing a subsequent infection caused by identical bacteria [17-20]. K. quasipneumoniae were initially thought to be asymptomatic carriage isolates until more recent reports highlighted their potential virulence and increased drug resistance [17-20].

K. pneumoniae has been extensively studied in many different animal models, including models for bloodstream infections, pneumonia, liver abscess, digestive and urinary tract infections [21,22]. On the other hand, little is known about closely related species recently separated from $K$. pneumoniae such as $K$. variicola and $K$. quasipneumoniae. There were only limited animal studies with $K$. variicola such as experiments on the bacteria's ability to colonize the intestinal tract and the host immune system response against this opportunistic pathogen [23,24]. K. quasipneumoniae has been detected in the clinical settings during hospital infections, however, the species has not been tested in animal efficacy models, and mechanisms of infection by this bacterium are poorly understood. Therefore, the first goal of our study was to establish an animal model of $K$. quasipneumoniae intestinal infection, in particular, identify the conditions that allow bacteria to successfully colonize the mouse intestinal tract. We demonstrate here that for successful colonization of mice gut by $K$. quasipneumoniae, the disturbance of natural gut microflora using antibiotic pre-treatment is necessary and sufficient.

Bacteria were not detected in the bacterial control group without prior antibiotic treatment (judged by khe amplification). Similar findings were observed in other Klebsiella mouse models where amoxicillin disruption of the gut microbiota was accompanied required for gut colonization and an enhancement of the virulence of $K$. variicola [24]. Other studies illustrated that mouse models of $K$. pneumoniae and treatment with antibiotics led to changes in the host microbiota and the development of a transient supershedder phenotype, which displays the enhanced transmission efficiency of bacteria in the GI tract $[25,26]$. Allegedly, the natural host microbiota activates the defence mechanisms against $K$.

quasipneumoniae and inhibits colonization, whereas reduced microbial diversity might promote the ability to infect. However, the exact mechanisms causing K. quasipneumoniae colonization needs further investigation.

It is known that bacteriocins have antimicrobial activities against pathogenic microorganisms $[27,28]$. Previous studies have identified various classes of bacteriocins (e.g.: colicin-like bacteriocins, tailocins, peptide microcins) and their potential applications in food technology, treatments of infection, and cancer [29-31]. Earlier, we demonstrated the antibacterial efficacy of purified klebicins in vitro using clinical Klebsiella isolates. Recombinant bacteriocin Kvarla was identified as one of the most active klebicins; it showed the highest activity against $K$. quasipneumoniae strains and was also tested in vivo in a nonmammal animal model, Galleria mellonella larvae, demonstrating significant antibacterial effect [14]. In this study, we developed a mouse model of intestinal tract infection using $K$. quasipneumoniae with the main purpose of investigating the potential of klebicin as a clinical antimicrobial. 
The authors determined the most effective coating for bacteriocin needed for delivery of the highest concentrations of the klebicin to the large colon. The $\mathrm{pH}$ in the $\mathrm{Gl}$ tract is a substantial factor, affecting the solubility and stability of the drug and absorption through the intestinal tract mucosa. It can vary depending on the diet type, fed or fasted states, drugs, microbiota diversity, stress, and daily fluid intake. Henceforth, unsuitable $\mathrm{pH}$ causes the precipitation of drugs from the solution or the degradation of labile compounds [32-34]. Correspondingly, an assessment of $\mathrm{pH}$ levels in the $\mathrm{Gl}$ tract was included in our study. We distinguished the increased $\mathrm{pH}$ level of the rectum content sample in the $K$. quasipneumoniae colonized mice groups treated with antibiotics. However, mice without antibiotics did not show any change in pH levels. Similar results were obtained by Shimizu and colleagues in ICR mice housed obtaining specific pathogen-free conditions, there the $\mathrm{pH}$ of the cecum and colon increased exceedingly in the experimental groups treated with antibiotics [35]. Therefore, the $\mathrm{pH}$ measurements of the $\mathrm{Gl}$ tract were taken into account when choosing the most effective coating for Kvarla delivery.

In this study recombinant bacteriocins Kvarla ability to eliminate the intestinal tract infection was judged using khe gene quantification. We identified that both concentrations $(100 \mu \mathrm{g}$ and $1000 \mu \mathrm{g})$ of coatedKvarla significantly reduced the infection in the GI tract of mice models. However, in our study, we did not achieve full eradication of the $K$. quasipneumoniae. Kvarla was encapsulated with Eudragit S100 releasing klebicin at $\mathrm{pH}$ above 7 and administered by oral gavage to infected ( $K$. quasipneumoniae) mice. Debatably, klebicin activity could be suppressed or significantly lowered because of the gut microflora disruption or not full eradication, as well as, dependence on the $\mathrm{pH}$ level, which can fluctuate throughout the $\mathrm{GI}$ tract for various reasons (e.g. fasting state). Recently, a similar study was published describing the use of encapsulated colicins for the eradication of $E$. coli in mice [36.] Colicins encapsulated into hydrogel particles were shown to be released from the protective coat at $\mathrm{pH}$ above 5 and reduce colonizing $E$. coli numbers in the gut and in feces, although complete eradication of the pathogen was not achieved [36]. Consequently, further research on klebicin formulation for the most efficient release in the lower intestinal tract is necessary. Importantly, new formulations for oral delivery, preferably using approved formulation agents such as Eudragit, should be studied in validated preclinical animal models to further optimize efficacy of bacteriocins as antibacterials for intestinal infections.

\section{Conclusions}

This study demonstrated that successful colonization of the mouse intestinal tract by $K$. quasipneumoniae can be achieved but it requires the eradication of gut resident microbiota with an antibiotic. We also evaluated the antimicrobial activity of the orally delivered Eudragit S100-formulated klebicin in the mouse intestinal tract and show that thus formulated bacteriocins could be employed as oral antimicrobials for efficient control of antibiotic-resistant Klebsiella.

\section{List Of Abbrevations}

PBS - phosphate-buffered saline 
GI - gastrointestinal

khe-haemolysin gene

HAl - hospital-acquired infection

pen - penicillin

strep - streptomycin

met - metronidazole

SGF - sarcoma grow factor

SDS - sodium dodecyl sulfate

MW - molecular weight

DNA - Deoxyribonucleic acid

RNA - Ribonucleic acid

cDNA - complementary Deoxyribonucleic acid

qRT-PCR - qualitative real-time polymerase chain reaction

CFU - colony-forming unit

\section{Declarations}

Ethical approval: This article does not contain any studies with human participants performed by any of the authors.

Consent for publication: Not applicable.

Availability of data and materials: All data generated during this study are included in this article.

Competing interests: The authors declared that they have no competing interests.

Funding: This work was supported by the Lithuanian Business Support Agency grant J05-LVPA-K-030011 „Antimicrobial substance for treatment of Klebsiella infections".

\section{AUTHOR'S INFORMATION}

Authors' contributions: IK, RR carried out the experiment, derived the models, analysed samples and data, interpreted the results, drafted the manuscript, prepared the figures, edited the final version of the manuscript; ED, AM performed the experiments and analyzed the data; JK and JS edited the final version 
of the manuscript and contributed to the conception and design of the research; JB contributed to the initial part of the experiment related to pharmaceutics; VP contributed to the animal models and experimental layout; AR and YG contributed to the conception and design of the research, interpreted the results, and approved the final version of the manuscript. All authors discussed the results and contributed to the final manuscript.

Acknowledgments: Not applicable.

\section{ETHICS APPROVAL}

All procedures performed in studies involving animals were in accordance with Directive 2010/63/EU and the ethical standards of Lithuanian University of Health Sciences (approved by State Food and Veterinary Service; No. G2-119) at which the studies were conducted.

\section{References}

1. William J. Barson, Amy Leber. Principles and Practice of Pediatric Infectious Diseases. Klebsiella and Raoultella Species (Fifth Edition). Elsevier. 2018; doi.org/10.3389/fmicb.2021.670535.

2. Monegro AF, Muppidi V, Regunath H. Hospital Acquired Infections. 2020 Sep 3. In: StatPearls [Internet]. Treasure Island (FL): StatPearls Publishing; 2021; PMID: 28722887.

3. Imai K, Ishibashi N, Kodana M, Tarumoto N, Sakai J, Kawamura T, Takeuchi S, Taji Y, Ebihara Y, Ikebuchi K, Murakami T, Maeda T, Mitsutake K, Maesaki S. Clinical characteristics in blood stream infections caused by Klebsiella pneumoniae, Klebsiella variicola, and Klebsiella quasipneumoniae: a comparative study, Japan, 2014-2017. BMC Infect Dis. 2019; doi: 10.1186/s12879-019-4498-x.

4. Hala S, Antony CP, Alshehri M, Althaqafi AO, Alsaedi A, Mufti A, Kaaki M, Alhaj-Hussein BT, Zowawi HM, Al-Amri A, Pain A. First report of Klebsiella quasipneumoniae harboring blaKPC-2 in Saudi Arabia. Antimicrob Resist Infect Control. 2019; doi: 10.1186/s13756-019-0653-9. PMID: 31890159.

5. Long SW, Linson SE, Ojeda Saavedra M, Cantu C, Davis JJ, Brettin T, Olsen RJ. Whole-Genome Sequencing of Human Clinical Klebsiella pneumoniae Isolates Reveals Misidentification and Misunderstandings of Klebsiella pneumoniae, Klebsiella variicola, and Klebsiella quasipneumoniae. MSphere. 2017; doi: 10.1128/mSphere Direct.00290-17.

6. Perlaza-Jiménez L, Wu Q, Torres VVL, Zhang X, Li J, Rocker A, Lithgow T, Zhou T, Vijaykrishna D. Forensic genomics of a novel Klebsiella quasipneumoniae type from a neonatal intensive care unit in China reveals patterns of colonization, evolution and epidemiology. Microb Genom. 2020; doi: 10.1099/mgen.0.000433.

7. Mathers AJ, Crook D, Vaughan A, Barry KE, Vegesana K, Stoesser N, Parikh HI, Sebra R, Kotay S, Walker AS, Sheppard AE. Klebsiella quasipneumoniae Provides a Window into Carbapenemase Gene Transfer, Plasmid Rearrangements, and Patient Interactions with the Hospital Environment. Antimicrob Agents Chemother. 2019; doi:10.1128/ AAC.02513-18. 
8. Suzuki Y, Ida M, Kubota H, Ariyoshi T, Murakami K, Kobayashi M, Kato R, Hirai A, Suzuki J, Sadamasu K. Multiple $\beta$-Lactam Resistance Gene-Carrying Plasmid Harbored by Klebsiella quasipneumoniae Isolated from Urban Sewage in Japan. MSphere. 2019; doi: 10.1128/mSphere.00391-19.

9. Ghequire MGK, De Mot R. Turning Over a New Leaf: Bacteriocins Going Green. Trends Microbiol. 2018;26(1):1-2.

10. Zou J, Jiang H, Cheng H, Fang J, Huang G. Strategies for screening, purification and characterization of bacteriocins. Int J Biol Macromol. 2018; 117:781-9.

11. Cascales E, Buchanan SK, Duché D, Kleanthous C, Lloubès R, Postle K, Riley M, Slatin S, Cavard D. Colicin biology. Microbiol Mol Biol Rev. 2007;71(1):158-229.

12. Francino MP. Antibiotics and the Human Gut Microbiome: Dysbioses and Accumulation of Resistances. Front Microbiol. 2016; doi: 10.3389/fmicb.2015.01543.

13. Behrens HM, Six A, Walker D, Kleanthous $C$. The therapeutic potential of bacteriocins as protein antibiotics. Emerg Top Life Sci. 2017;1(1):65-74.

14. Denkovskienė E, Paškevičius Š, Misiūnas A, Stočkūnaitė B, Starkevič U, Vitkauskienė A, HahnLöbmann S, Schulz S, Giritch A, Gleba Y, Ražanskienė A. Broad and Efficient Control of Klebsiella Pathogens by Peptidoglycan-Degrading and Pore-Forming Bacteriocins Klebicins. Sci Rep. 2019; doi: 10.1038/s41598-019-51969-1.

15. Whitaker DM, Reichley SR, Griffin MJ, Prager K, Richey CA, Kenelty KV, Stevens BN, Lloyd-Smith JO, Johnson CK, Duignan P, Johnson S, Rios C, DeLong R, Halaska B, Rust L, Byrne BA, Struve C, Barnum $S$, Soto E. Hypermucoviscous Klebsiella Pneumoniae isolates from stranded and wild-caught marine mammals of the us pacific coast: prevalence, phenotype, and genotype. J Wildl Dis. 2018;54(4):65970.

16. Hartman LJ, Selby EB, Whitehouse CA, Coyne SR, Jaissle JG, Twenhafel NA, Burke RL, Kulesh DA. Rapid real-time PCR assays for detection of Klebsiella pneumoniae with the rmpA or magA genes associated with the hypermucoviscosity phenotype: screening of nonhuman primates. J Mol Diagn. 2009;11(5):464-71.

17. Nirwati H, Sinanjung K, Fahrunissa F, Wijaya F, Napitupulu S, Hati VP, Hakim MS, Meliala A, Aman AT, Nuryastuti T. Biofilm formation and antibiotic resistance of Klebsiella pneumoniae isolated from clinical samples in a tertiary care hospital, Klaten, Indonesia. BMC Proc. 2019; doi: 10.1186/s12919019-0176-7.

18. Lerminiaux NA, Cameron ADS. Horizontal transfer of antibiotic resistance genes in clinical environments. Can J Microbiol. 2019;65(1):34-44.

19. Bengtsson-Palme J, Kristiansson E, Larsson DGJ. Environmental factors influencing the development and spread of antibiotic resistance. FEMS Microbiol Rev. 2018; doi: 10.1093/femsre/fux053.

20. Martin RM, Bachman MA. Colonization, Infection, and the Accessory Genome of Klebsiella pneumoniae. Front Cell Infect Microbiol. 2018; doi: 10.3389/fcimb.2018.00 004. 
21. Fang CT, Chuang YP, Shun CT, Chang SC, Wang JT. A novel virulence gene in Klebsiella pneumoniae strains causing primary liver abscess and septic metastatic complications. J Exp Med. 2004;199(5):697-705.

22. Hsieh PF, Lu YR, Lin TL, Lai LY, Wang JT. Klebsiella pneumoniae Type VI Secretion System Contributes to Bacterial Competition, Cell Invasion, Type-1 Fimbriae Expression, and In Vivo Colonization. J Infect Dis. 2019;219(4):637-47.

23. Lin H, Wang Q, Liu L, Chen Z, Das R, Zhao Y, Mao D, Luo Y. Colonization of Mice With AmoxicillinAssociated Klebsiella variicola Drives Inflammation via Th1 Induction and Treg Inhibition. Front Microbiol. 2020; doi: 10.3389/fmicb.2020.01256.

24. Potter RF, Lainhart W, Twentyman J, Wallace MA, Wang B, Burnham CA, Rosen DA, Dantas G. Population Structure, Antibiotic Resistance, and Uropathogenicity of Klebsiella variicola. mBio. 2018; doi: 10.1128/mBio.02481-18.

25. TM, Bray AS, Nagpal RK, Caudell DL, Yadav H, Zafar MA. Animal Model To Study Klebsiella pneumoniae Gastrointestinal Colonization and Host-to-Host Transmission. Infect Immun. 2020; doi:10.1128/IAI.00071-20.

26. Sequeira RP, McDonald JAK, Marchesi JR, Clarke TB. Commensal Bacteroidetes protect against Klebsiella pneumoniae colonization and transmission through IL-36 signalling. Nat Microbiol. 2020;5(2):304-13.

27. Ahmad V, Khan MS, Jamal QMS, Alzohairy MA, Al Karaawi MA, Siddiqui MU. Antimicrobial potential of bacteriocins: in therapy, agriculture and food preservation. Int J Antimicrob Agents. 2017;49(1):111.

28. Simons A, Alhanout K, Duval RE. Bacteriocins, Antimicrobial Peptides from Bacterial Origin: Overview of Their Biology and Their Impact against Multidrug-Resistant Bacteria. Microorganisms. 2020; doi: 10.3390/microorganisms8050639.

29. Yang SC, Lin $\mathrm{CH}$, Sung CT, Fang JY. Antibacterial activities of bacteriocins: application in foods and pharmaceuticals. Front Microbiol. 2014; doi: 10.3389/fmicb.2014.00241.

30. Lopetuso LR, Giorgio ME, Saviano A, Scaldaferri F, Gasbarrini A, Cammarota G. Bacteriocins and Bacteriophages: Therapeutic Weapons for Gastrointestinal Diseases? Int J Mol Sci. 2019; doi: 10.3390/ijms20010183.

31. Soltani S, Hammami R, Cotter PD, Rebuffat S, Said LB, Gaudreau H, Bédard F, Biron E, Drider D, Fliss I. Bacteriocins as a new generation of antimicrobials: toxicity aspects and regulations. FEMS Microbiol Rev. 2021; doi: 10.1093/femsre/fuaa039.

32. McConnell EL, Basit AW, Murdan S. Measurements of rat and mouse gastrointestinal pH, fluid and lymphoid tissue, and implications for in-vivo experiments. J Pharm Pharmacol. 2008; 60(1):63-70.

33. Hatton GB, Yadav V, Basit AW, Merchant HA. Animal Farm: Considerations in Animal Gastrointestinal Physiology and Relevance to Drug Delivery in Humans. J Pharm Sci. 2015; 104(9):2747-76.

34. Kohl KD, Stengel A, Samuni-Blank M, Dearing MD. Effects of anatomy and diet on gastrointestinal pH in rodents. J Exp Zool A Ecol Genet Physiol. 2013;319(4):225-9. 
35. Shimizu K, Seiki I, Goto Y, Murata T. Measurement of the Intestinal pH in Mice under Various Conditions Reveals Alkalization Induced by Antibiotics. Antibiotics (Basel). 2021; doi: 10.3390/antibiotics10020180.

36. Carpena N, Richards K, Gonzalez TDJB, Blas AB, Housden NG, Gerasimidis K, Milling SWF, Douce G, Malik DJ, Walker D. Targeted Delivery of Narrow-Spectrum Protein Antibiotics to the Lower Gastrointestinal Tract in a Murine Model of Escherichia coli Colonization. Front Microbiol. 2021; doi.org/10.3389/fmicb.2021.670535.

\section{Figures}

\section{Figure 1}

\section{Experimental design of $K$. quasipneumoniae colonization and pH of $\mathrm{GI}$.}

A - The design of the study of mice gut colonization by K. quasipneumoniae. $1^{\text {st }}$ Vehicle-only control group with natural microbiota ( $n=3) ; 2^{\text {nd }}$ Bacterial control group $(n=3) ; 3^{\text {rd }}, 4^{\text {th }}$ antibiotic pre-treated groups ((i) penicillin, streptomycin (pen_strep group) or (ii) penicillin, streptomycin, and metronidazole (pen_strep_met group)). Samples were collected on circled days. B - The pH values measured in the samples of rectum excreta throughout the layout of the experiment protocol in order to determine the changes in the GI tract using different substances. The control group showed an average of $7.34 \mathrm{pH}$ with the lowest being $6.99 \mathrm{pH}$ and the highest $7.76 \mathrm{pH}$; the infected mice group without antibiotics showed almost no changes in $\mathrm{pH}$ measures through the days (av. $7.27 \mathrm{pH}) ; K$. quasipneumoniae infected group was treated with antibiotic therapy (penicillin, streptomycin) and showed stable results (av. $7.7 \mathrm{pH})$ with an exception on the $6^{\text {th }}$ day of the experiment $(7.94 \mathrm{pH})$; the last group, which was infected with $K$. quasipneumoniae showed the most noticeable changes during the combined antibiotic (penicillin, streptomycin, metronidazole) treatment and bacterial colonization with the average of $7.44 \mathrm{pH}$ fluctuating from $6.57 \mathrm{pH}$ to $8.11 \mathrm{pH}$. No significant differences were found in or between the groups. C Overall differences in values of stomach, duodenum, and rectum of $\mathrm{pH}$ measurements between groups. The lowest $\mathrm{pH}$ was seen in the stomach (2.34 - 5.46; avg. 3.3). The $\mathrm{pH}$ of the small intestine varied between 5.97 and 6.77 (avg. 6.5), with the large intestine showing the highest $\mathrm{pH}(6.74-8.15$; avg. 7.4). A significant difference $(\mathrm{p}<0.05)$ in $\mathrm{pH}$ measures was found in the duodenum between $3^{\text {rd }}$ and $4^{\text {th }}$ groups $(\#)$, as well as between $1^{\text {st }}$ group and $3^{\text {rd }}(*)$ in rectum. 


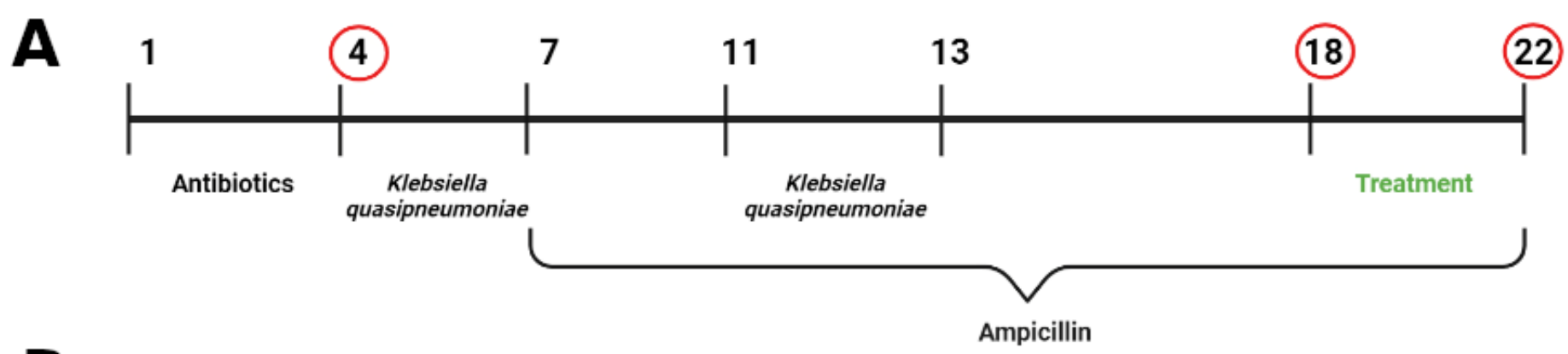

B DNA

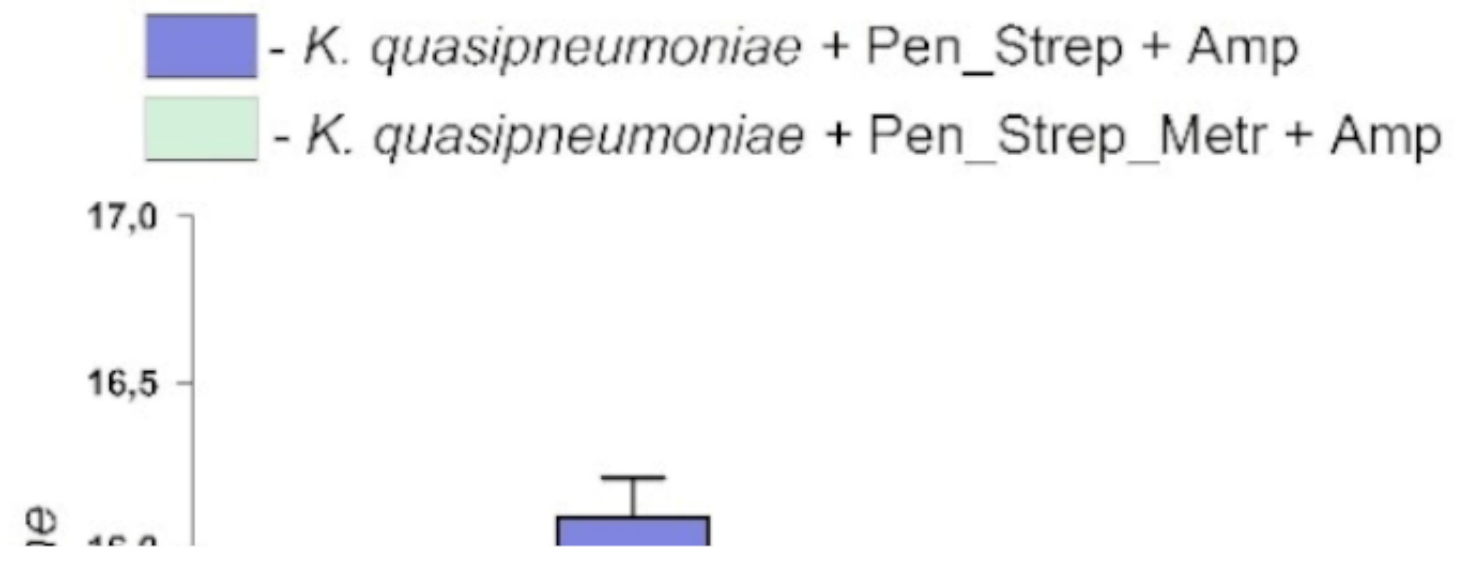

Figure 2

Experimental design of $K$. quasipneumoniae therapy and assessment of Klebsiella quasipneumoniae colonization

A - The design of the study of mice gut colonization by $K$. quasipneumoniae and Kvarla treatment. All four experimental groups had antibiotic pretreatment, ampicillin therapy, bacterial administration, and 
different treatment for infection (PBS; uncoated-Kvarla; Eudragit S100-coated Kvarla $100 \mu$ g; Eudragit S100-coated Kvarla $1000 \mu \mathrm{g}$ ). Samples were collected on circled days. B - Amplification of $\boldsymbol{k h e}$ gene in mice faeces after the introduction of $K$. quasipneumoniae. khe gene was detected by RT-PCR. A lower CT value indicates a higher number of bacteria. The $4^{\text {th }}$ day's samples were used as a control group because they did not show any bacterial colonization. Statistically significant differences between mice groups (K. quasipneumoniae + Pen_Strep + Amp vs K. quasipneumoniae + Pen_Strep_Met + Amp) were not determined. Pen - penicillin, Strep - streptomycin, Met - metronidazole, Amp - ampicillin.

\section{Figure 3}

\section{Evaluation of stability and activity of Kvarla after in vitro gastric digestion assay.}

A - Evaluation of residual activity by agar diffusion assay. Protein samples were incubated at $37^{\circ} \mathrm{C}, 200$ rpm in gastric digestion buffer (pepsin:protein ratio 1:40). Aliquots of reaction (50 $\mu \mathrm{l})$ were removed at different time points $(0.5,5,10,20,30$, and $60 \mathrm{~min})$ and digestion was stopped by the addition of $0,5 \mathrm{M}$ ammonium bicarbonate to inactivate pepsin. The $\mathrm{pH}$ of samples with coated Kvarla was adjusted to 8 to get Eudragit coat dissolved. The dilutions of all samples by ratio 1:2 were made in distilled water and $5 \mu \mathrm{L}$ drops of diluted samples were applied on K.quasipneumoniae DSM28212 MHA plates for soft agar overlay assay. B - SDS-PAGE of Kvarla after simulated gastric digestion. The $16 \%$ TRIS-Tricine gels; unstained marker - PageRuler ${ }^{\text {TM }}$ Unstained Low Range Protein Ladder (ThermoFisher), $10 \mu \mathrm{l}$ of each sample loaded per line. Pepsin appears as the stable band between 30 and $42 \mathrm{kDa}$ markers (green arrow). The red arrow indicates the full-size Kvarla. Exposure of Kvarla to pepsin (1:40 pepsin:lysin wt:wt) in acidic SGF results in the rapid breakdown of the protein to lower MW degradation products. Sampling times are shown in minutes. 


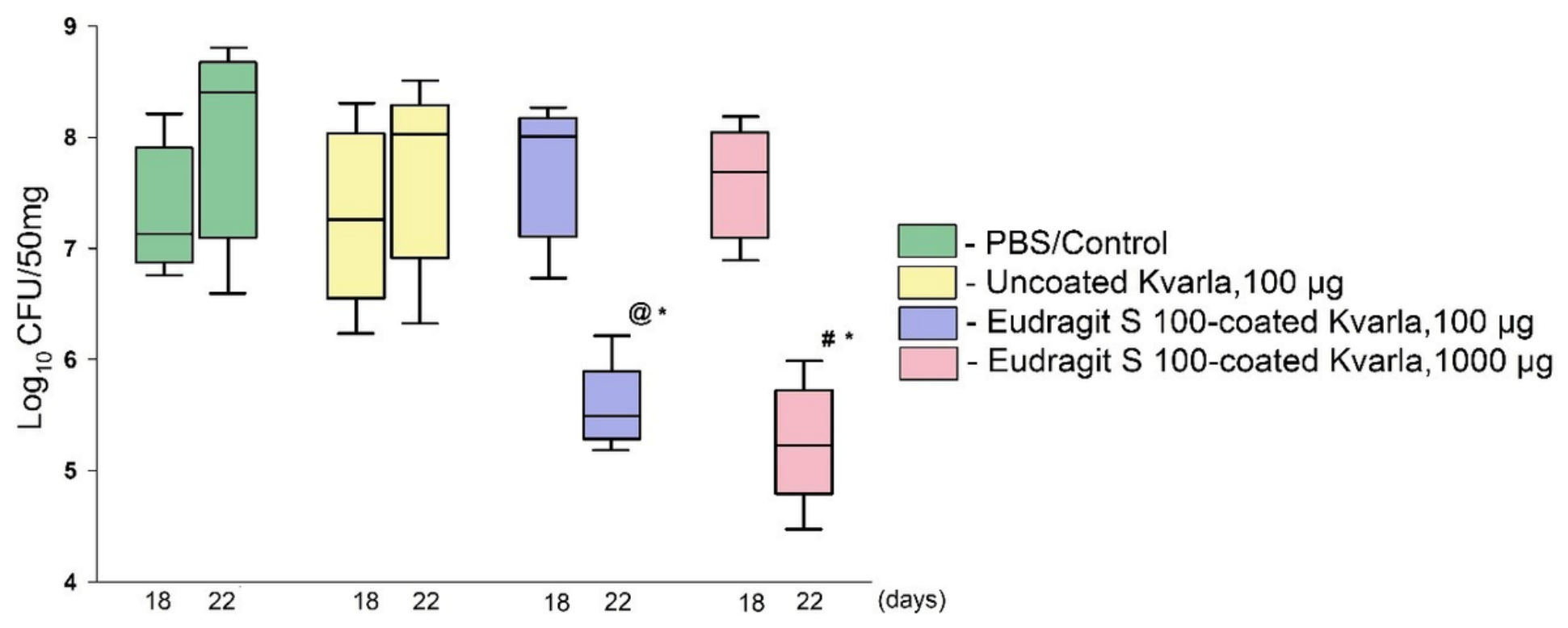

Figure 4

\section{Bacterial counts in GI tract after Kvarla therapy.}

khe gene from DNA templates was determined using RT-PCR. A lower CT value indicates a higher number of bacteria (see Standard Curve). khe has not been detected in all study groups on the $4^{\text {th }}$ day. * Statistically significant differences between $18^{\text {th }}$ and $22^{\text {nd }}$ days in all the experimental groups treated by Eudragit S100-coated Kvarla, p<0.05. @ PBS (control) and uncoated-Kvarla $(100 \mu \mathrm{g})$ treated mice vs Eudragit S100-coated Kvarla $(100 \mu \mathrm{g})$ treated group on the $22^{\text {nd }}$ day, $\mathrm{p}<0.05 .{ }^{*} \mathrm{PBS}$ (control) and Uncoated Kvarla $(100 \mu \mathrm{g})$ treated mice vs Eudragit S100-coated Kvarla $(1000 \mu \mathrm{g})$ treated group on the $22^{\text {nd }}$ day, $p<0.05$. 